Reply

\title{
Life Cycle Assessment Study May Exclude Less Significant Processes from the Scope-Reply to Comment by Heijungs and Cucurachi
}

\author{
Andrzej Marcinkowski * (D) and Joanna Kopania (D) \\ Faculty of Management and Production Engineering, Lodz University of Technology, 90-924 Lodz, Poland; \\ joanna.kopania@p.lodz.pl \\ * Correspondence: andrzej.marcinkowski@p.lodz.pl
}

Citation: Marcinkowski, A.;

Kopania, J. Life Cycle Assessment

Study May Exclude Less Significant

Processes from the Scope-Reply to

Comment by Heijungs and

Cucurachi. Energies 2021, 14, 1954.

https://doi.org/10.3390/en14071954

Academic Editor: Dimitris

Katsaprakakis

Received: 22 March 2021

Accepted: 30 March 2021

Published: 1 April 2021

Publisher's Note: MDPI stays neutral with regard to jurisdictional claims in published maps and institutional affiliations.

Copyright: (c) 2021 by the authors. Licensee MDPI, Basel, Switzerland. This article is an open access article distributed under the terms and conditions of the Creative Commons Attribution (CC BY) license (https:/ / creativecommons.org/licenses/by/ $4.0 /)$.
In the comment of Heijungs and Cucurachi [1] to our recent study (Marcinkowski and Kopania [2]), the commentators raised a few remarks. The main question concerned the restricted scope of the study, as sound-related impact considers only noise due to steam discharge and traffic noise and excludes processes such as production and disposal.

The first life cycle assessment (LCA) stage includes scope definition. Within this step, a decision about which processes should be taken into account in the analyses is made. Usually, this choice is based on the significance of the impact associated with individual processes and their contribution to the whole environmental effect. As a result, processes with relatively low impact are excluded from the analyses. In our study, this scope was considered from two perspectives: first, concerning "traditional" impact categories encompassed by most life cycle impact assessment methods (resources extraction, emission, etc., indicated by red arrows in Figure 1) and, second, relating to other categories that are usually omitted, represented by noise (depicted in Figure 1 by green arrows). Within the second perspective, the most relevant processes were chosen given the duration of individual processes and the number of people exposed to noise. With regard to the functional unit, defined as one item of a steam discharge noise silencer, processes such as raw material extraction, processing, manufacturing, and disposal are carried out only once for a relatively short period of time. Moreover, they usually take place in industrial zones located far from noise-protected areas and workers operating in noisy worksites are often equipped with personal hearing protectors. Having considered the circumstances outlined above, an assumption was made that the processes listed above would be excluded from the analysis. It was assumed that processes occurring over a longer period of time (ten years) accounted for a predominant proportion of the total noise effect. As a result, only steam discharge and traffic were selected as the most significant contributors to the overall noise impact. However, within the first perspective, the rest of the processes (with relatively short duration) were taken into account as well. The entire life cycle was thus taken into account in the analysis performed.

At the end of their comment, Heijungs and Cucurachi (2021) questioned the method selected for the analysis conducted by Marcinkowski and Kopania [2] and the methods presented in previous studies (Ongel [3]; Meyer et al. [4]). The commentators stated that these methods failed to add sound generated by different processes included in the life cycle. The method proposed by Cucurachi et al. [5] (C12) represents a suitable solution to this problem. However, we decided not to apply it in our study for the following reason(s). The overestimation of noise impact by a few orders of magnitude, reported by Meyer et al. [4], implies serious deficiencies of C12, demanding further developments of the model. Therefore, we adopted another method that allowed us to achieve our goal, which is a comparison of the health benefits resulting from the reduction in steam discharge noise with the environmental burden associated with the production and disposal of noise silencers, providing the noise reduction considered. Moreover, the method presented 
enabled us to add the effects of noise generated by different sources (steam discharge and traffic) within independent time periods and expressed the results both as midpoint and endpoint indicators.

To conclude, our study (Marcinkowski and Kopania [2]) was oriented towards carrying out a preliminary analysis of the problem, allowing us to obtain first-order approximation results. We are aware that our site-specific case study represents a particular contribution to the field, but simultaneously, this can be seen as an indication of the importance of the problem of noise effects, especially in the context of the LCA method. We therefore cannot agree that our article represents a step back. However, we are pleased to see that studies on the inclusion of noise effects in LCA are drawing significant attention from researchers, which will lead to future and interesting developments in this field.

\section{References}

1. Heijungs, R.; Cucurachi, S. One process does not make a life cycle-Comment to Marcinkowski and Kopania. Energies 2021. unpublish.

2. Marcinkowski, A.; Kopania, J. Environmental performance of noise reduction system in cogeneration plants. A life cycle assessment study. Energies 2021, 14, 1324. [CrossRef]

3. Ongel, A. Inclusion of noise in environmental assessment of road transportation. Environ. Model. Assess. 2016, 21, 181-192. [CrossRef]

4. Meyer, R.; Benetto, E.; Igos, E.; Lavandier, C. Analysis of the different techniques to include noise damage in life cycle assessment. A case study for car tires. Int. J. Life Cycle Assess. 2017, 22, 744-757. [CrossRef]

5. Cucurachi, S.; Heijungs, R.; Ohlau, K. Towards a general framework for including noise impacts in LCA. Int. J. Life Cycle Assess. 2012, 17, 471-487. [CrossRef] [PubMed] 